\title{
CICLO DE AVALIAÇÃO DA EDUCAÇ̃̃O BÁSICA DO CEARÁ: PRINCIPAIS RESULTADOS
}

ALESSIO COSTA LIMA

\section{RESUMO}

A ênfase em avaliação educacional tem sido a tônica das políticas educacionais contemporâneas, com vistas a subsidiar ações de planejamento e monitoramento dos sistemas educacionais. Em sintonia com esse movimento, a partir de 2007, o Ceará intensificou esforços e investimentos na ampliação do Spaece, que passou a ser realizado anualmente de forma censitária e universal. Com efeito, a realização deste ensaio objetiva analisar a política de avaliação educacional implementada pelo Estado no período de 2007 a 2010, as principais ações desenvolvidas, os resultados produzidos, a forma de comunicação e utilização de tal política. Os resultados revelam uma tendência de melhoria no desempenho dos alunos em todas as séries e disciplinas avaliadas, mostrando-se mais acentuada nos anos iniciais, ou seja, nos $2^{\circ}$ e $5^{\circ}$ anos, e com menor intensidade nos anos finais.

PALAVRAS-CHAVE AVALIAÇÃO DA EDUCAÇÃO • POLÍTICAS EDUCACIONAIS・ QUALIDADE DO ENSINO • SPAECE. 


\section{RESUMEN}

El énfasis en la evaluación educativa ha sido la tónica de las políticas contemporáneas del área, con el fin de subsidiar acciones de planeamiento y monitoreo de los sistemas educativos. En sintonía con ese movimiento, a partir de 2007, el estado de Ceará intensificó esfuerzos e inversiones en la ampliación del Spaece, que comenzó a realizarse anualmente de forma censal y universal. La realización de este ensayo tiene como objetivo analizar la política de evaluación educativa implementada por ese Estado de 2007 a 2010, las principales acciones desarrolladas, los resultados obtenidos, la forma de comunicación y utilización. Los resultados revelan una tendencia de mejoría en el desempeño de los alumnos en todos los niveles y asignaturas evaluadas, mostrándose más acentuada en los años iniciales,

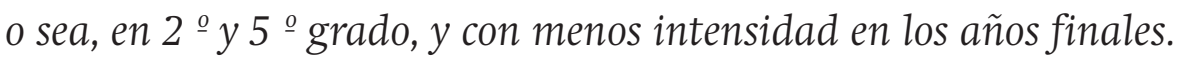

PALABRAS CLAVE EVALUACIÓN DE LA EDUCACIÓN •POLÍTICAS

DE EDUCACIÓN • CALIDAD DE LA EDUCACIÓN • SPAECE.

\section{ABSTRACT}

The emphasis in Educational Evaluation has been the tone of contemporary education policies in order to support planning and monitoring actions of education systems. In line with this movement, as of 2007, Ceará has intensified its efforts and investments in the expansion of Spaece, which is now held annually on a census and universal basis. Indeed, this essay aims to examine the policy of educational assessment implemented by the State of Ceará between 2007 and 2010, the main actions undertaken, the results produced, the form of communication and use. The results show a trend toward improvement in student achievement in all grades and subjects evaluated, mainly in the early years, ie the 2nd and 5th grades, and less so in the final grades.

KEYWORDS EDUCATIONAL EVALUATION • EDUCATIONAL POLICIES • TEACHING QUALITY • SPAECE. 


\section{INTRODUÇÃO}

A educação no contexto atual, mais que um direito subjetivo de todo cidadão, é condição para sua inclusão social. Para tanto, faz-se imprescindível que o sistema educacional de um país proporcione uma educação com qualidade capaz de prover a grande maioria, senão a todos, bem como direitos políticos e acesso ao mercado de trabalho em condições minimamente dignas.

Percebe-se, nas últimas décadas, um grande movimento no sentido de garantir a todos o acesso à educação, mas que nem sempre se fez acompanhar do desenvolvimento e da melhoria dos indicadores sociais e de qualidade de vida da população. As políticas educacionais de acesso, nos mais variados modelos e formas, têm, de certa forma, assegurado mecanismos de reprodução da lógica dos sistemas educacionais tradicionais, ampliando em alguns casos a segregação interna dos sistemas de ensino, criando novas dinâmicas de exclusão, de maneiras mais complexas e difusas.

Para grandes setores da população, a permanência na escola,

mesmo representando uma grande conquista social, esteve

longe de se converter em oportunidade de acesso a um direito efetivo. As últimas cinco décadas da nossa história 
educacional podem ser compreendidas como um processo

de expansão das oportunidades de acesso à escola, num contexto de persistente negação do direito à educação para as grandes maiorias. (GENTILI, 2008, p. 29)

Mais do que prover o acesso de todos à educação, é preciso operar mudanças profundas nas estruturas sociais, no sentido de reconhecer e absorver um novo paradigma de uma sociedade plenamente educada. A superação desse desafio, sobretudo nos países menos desenvolvidos, pressupõe, além da necessidade de avanços em vários outros aspectos de conjuntura macro, transformações nos modelos e práticas educacionais vigentes, assim como no acompanhamento e monitoramento dos serviços educacionais ofertados, com base em dados, indicadores e informações significativas e confiáveis, capazes de retratar as condições de efetividade, qualidade e equidade do sistema educacional. Na consecução desse objetivo, a avaliação educacional ganha relevo expressivo, assumindo um importante papel na definição e no rumo das políticas públicas educacionais.

Assim, a ênfase em processos de avaliação em larga escala é hoje considerada estratégica como subsídio indispensável para a formulação e monitoramento das políticas educacionais. Não há evidências de que nenhum sistema educacional que se preze e que esteja preocupado em melhorar a sua eficiência, equidade e a qualidade tenha ignorado a importância da avaliação como ferramenta eficaz de gestão.

Na França, por exemplo, a avaliação do sistema educacional cumpre a finalidade de fornecer aos responsáveis por esse sistema os meios de pilotar.

Trata-se de fornecer, a todos esses responsáveis, de todos os níveis - desde o Ministério ou o parlamento, em nível nacional, até cada docente em sua sala de aula -, as ferramentas que os ajudarão a regular sua política e suas ações, a avaliar os resultados e a modificar a orientação, se for necessário. (EMIN, 2005, p. 62)

Como se observa, a preocupação em avaliar sistemas educacionais com base em processos externos não é algo tão recente, sendo implementado em muitos países desde os anos de 1950, e, em alguns casos, remontando a décadas anteriores. 
Na América Latina e no Brasil, essa preocupação só começa a adquirir forma a partir dos últimos anos da década de 1980, com a incorporação do planejamento como estratégia de concepção das políticas públicas. Assim, a necessidade de realizar avaliações no campo educacional extrapolou o aspecto até então restrito à sala de aula e estendeu-se para outras dimensões, tais como sistemas, instituições, currículos, programas e políticas. É nesse contexto que a relação entre educação e desenvolvimento econômico passa a exigir análises mais globais e totalizantes, ganhando espaço as avaliações de sistemas e das instituições escolares. (LIMA, COELHO, SOARES, 2005, p. 138)

Dessa forma, especificamente no Brasil, a avaliação educacional passa a ser objeto de intenso debate e reflexão, tanto nos meios acadêmicos, como nos altos escalões das instâncias centrais do governo, responsáveis pela definição das políticas públicas educacionais, recebendo forte influência e incentivo dos organismos internacionais de financiamento. Essa discussão ganha corpo, dando origem ao sistema de avaliação do país, cujo primeiro levantamento foi realizado em 1990, passando a ser denominado posteriormente de Sistema Nacional de Avaliação da Educação Básica (Saeb).

O Saeb surge então com o objetivo de fazer um diagnóstico da situação de aprendizagem dos alunos ao final de cada ciclo de ensino, subsidiando assim a tomada de decisão no tocante à definição das políticas educacionais, em consonância com o pensamento de Cronbach (1963), em que a avaliação consiste em um processo que visa à coleta de diversas informações, com vista à tomada de diferentes tipos de decisões (VIANNA, 1989).

Coube ao Saeb também o papel de trabalhar a disseminação da cultura de avaliação educacional no âmbito dos sistemas de ensino. Dessa forma, os estados foram influenciados, passando inclusive a desenvolver sistemas próprios ao de avaliação, a exemplo do Ceará, um dos estados pioneiros na implantação de um sistema estadual de avaliação, cujo primeiro levantamento foi realizado em 1992, passando a ser denominado posteriormente de Sistema Permanente de Avaliação da Educação Básica do Ceará (Spaece). 
A partir de 2007, a Secretaria da Educação em sintonia com as diretrizes do governo do estado criou em sua estrutura organizacional a Coordenadoria de Avaliação e Acompanhamento da Educação (Coave), que tem, entre outras, a finalidade de definir políticas de avaliação e acompanhamento do sistema de ensino público, com foco na melhoria dos resultados educacionais. A referida coordenadoria está estruturada em três células, sendo a Célula de Avaliação do Desempenho Acadêmico (Ceade) responsável pela realização e coordenação do Spaece.

Com o firme propósito de criar um sistema de ensino mais justo e inclusivo, no qual as chances de aprendizado sejam iguais para todos, a Secretaria da Educação do Ceará (Seduc) fortaleceu visivelmente o seu sistema de avaliação, com o intuito de utilizar os resultados produzidos pelas avaliações como subsídio para intervenções destinadas a garantir o direito do aluno a uma educação pública de qualidade. Isso porque as informações geradas em cada ciclo do Spaece possibilitam orientar, no âmbito dos sistemas de ensino, a (re)formulação de políticas públicas voltadas à promoção da qualidade e equidade e, no âmbito das práticas que se realizam nas escolas, o planejamento de intervenções pedagógicas focalizadas nas reais necessidades de aprendizagem dos estudantes.

Partindo da premissa da relevância das avaliações produzidas pelo Spaece para o sistema educacional, este ensaio busca analisar a política de avaliação educacional no Ceará implementada no quadriênio 2007 a 2010, demonstrando os principais resultados obtidos e o que eles revelam. Elegendo como estratégia metodológica de investigação a pesquisa bibliográfica e documental, pretende-se descrever os contornos da política de avaliação educacional desenhada no período, mapeando o conjunto das ações desenvolvidas nessa área, bem como as informações produzidas, a forma de sua divulgação e uso. Espera-se que os elementos ora levantados e apresentados possam contribuir com o debate em prol da melhoria da qualidade e da equidade do sistema educacional público cearense. 


\section{O REDESENHO DO SPAECE A TRAJETÓRIA}

A trajetória do Spaece lhe confere certa maturidade e credibilidade que o consolida enquanto sistema de avaliação estadual, aceito e legitimado pela comunidade educacional, como referência na produção de indicadores tecnicamente confiáveis acerca do desempenho dos alunos da escola pública cearense, referenciado por várias produções de natureza acadêmica e/ou administrativa.

O início de suas primeiras avaliações, em 1992, foi um passo importante e ousado para a época, classificando-o como um dos primeiros sistemas estaduais de avaliação no País. Desde então, vem sendo aperfeiçoado, passando por sucessivas transformações de natureza conceitual e metodológica. Da mesma forma recebeu diferentes nomenclaturas até sua denominação atual como Sistema Permanente de Avaliação da Educação Básica do Ceará - Spaece. (LIMA, 2007, p. 207)

Enquanto sistema o Spaece objetiva, de forma geral, diagnosticar o desempenho dos alunos em diferentes áreas do conhecimento e níveis de escolaridade, bem como subsidiar a implementação, a reformulação e o monitoramento de políticas educacionais, contribuindo ativamente para a melhoria da qualidade da educação no estado. Mais especificamente esse sistema pretende também:

- Avaliar de forma universalizada todas as escolas da rede pública de ensino, localizadas nos 184 municípios cearenses, mediante a aplicação de instrumentos cognitivos (testes) e contextuais (questionários).

- Produzir informações sobre o desempenho escolar de cada aluno avaliado na educação básica e os fatores que se associam a esse desempenho, possibilitando a implementação de ações mais focalizadas.

- Levantar pistas acerca do grau de conhecimento do professor na disciplina que leciona, buscando a correlação entre as dificuldades do professor e as apresentadas pelos alunos.

- Possibilitar a todos os agentes envolvidos no processo educativo (alunos, professores, diretores, pais, administradores, técnicos e especialistas) um acompanhamento efetivo dos resultados obtidos pelas escolas. 
No período em estudo, ou seja, a partir de 2007, para atender às demandas e prioridades das políticas educacionais do novo governo, o Spaece passa por um processo de redesenho, sendo estruturado em três grandes vertentes avaliativas, a saber: Avaliação da Alfabetização - Spaece-Alfa ( $2^{\circ}$ ano); Avaliação do ensino fundamental ( $5^{\circ}$ e $9^{\circ}$ anos); e Avaliação do ensino médio $\left(1^{\mathrm{a}}, 2^{\mathrm{a}}\right.$ e $3^{\mathrm{a}}$ séries $)$.

\section{A AVALIAÇÃO DA ALFABETIZAÇÃO (SPAECE-ALFA)}

Esta nova vertente, o Spaece-Alfa, surge em decorrência da prioridade do atual governo para a alfabetização das crianças logo nos primeiros anos de escolaridade, expressa através do Programa Alfabetização na Idade Certa (Paic) a política central da atual gestão, que tem como foco principal a alfabetização das crianças até os sete anos de idade.

O Spaece-Alfa consiste numa avaliação externa, censitária, realizada anualmente para identificar e analisar o nível de proficiência em leitura dos alunos ao término do $2^{\circ}$ ano do ensino fundamental das escolas da rede pública, possibilitando construir um indicador de qualidade sobre a habilidade em leitura de cada aluno avaliado, bem como subsidiar os gestores na formulação de políticas de incentivo e redistribuição de recursos financeiros para os municípios e escolas.

\section{SPAECE-ALFA E O PRÊMIO ESCOLA NOTA DEZ}

Com o intuito de reconhecer o esforço daqueles municípios que conseguem alfabetizar adequadamente seus estudantes ao final do $2^{\circ}$ ano do ensino fundamental, o governo do estado institui o Prêmio Escola Nota 10. Trata-se de uma iniciativa destinada a premiar as 150 escolas públicas que obtiveram os melhores resultados de alfabetização, na avaliação externa do Spaece-Alfa, tendo por base o Índice de Desempenho Escolar Alfabetização (IDE-Alfa).

Para a premiação são considerados os seguintes critérios: a escola deve ter, no momento da avaliação, pelo menos 20 alunos matriculados no $2^{\circ}$ ano do ensino fundamental regular; ter obtido, numa escala de 0 a 10, média de Índice de Desempenho Escolar-Alfabetização (IDE-Alfa), situada no intervalo entre 8,5 e 10,0 pontos. O prêmio equivale ao valor de $R \$ 2.500,00$ por aluno avaliado. 


\section{A AVALIAÇÃO DO ENSINO FUNDAMENTAL}

A avaliação do ensino fundamental, de natureza externa e censitária, dá continuidade à série histórica do Spaece, com periodicidade bienal intercalada aos ciclos do Saeb. A referida avaliação é realizada nas séries finais de cada etapa do ensino fundamental, não só com a finalidade de diagnosticar o nível de proficiência, como também de analisar a evolução do desempenho dos alunos dos $5^{\circ}$ e $9^{\circ}$ anos e os fatores que se associam a esse desempenho, produzindo informações que possibilitem a definição de ações prioritárias de intervenção na rede pública.

\section{A AVALIAÇÃO DO ENSINO MÉDIO}

A avaliação do ensino médio, externa, realizada anualmente incluindo as três séries desse nível de ensino, envolve todas as escolas da rede estadual e seus anexos, localizadas nos 184 municípios cearenses. O conjunto de informações coletadas por essa avaliação permite montar uma tabela sobre os resultados da aprendizagem dos alunos, seus pontos fracos e fortes, e ainda sobre o perfil e a prática docente e de gestão dos professores e diretores das escolas estaduais. Em se tratando de uma avaliação com característica longitudinal, possibilita ainda acompanhar o progresso de aprendizagem de cada aluno ao longo do tempo.

Com efeito, a massa de informações produzidas pelas três vertentes avaliativas permite a elaboração de um diagnóstico mais preciso sobre a realidade educacional cearense, sobretudo, no que se refere às reflexões sobre a dinâmica de sala de aula para as correções de rumo que se fizerem necessárias. Assim, o sistema de avaliação no Ceará cumpre também sua função informativa, isto é, fornece informações para que professores e alunos conheçam os seus avanços e suas lacunas, fazendo com que ambos possam fazer as devidas correções de rumo, de forma que o ensino-aprendizagem se desenvolva com sucesso.

\section{A AVALIAÇÃO DO ENSINO MÉDIO \\ E O PRÊMIO APRENDER PRA VALER}

Como política de valorização e reconhecimento do esforço empreendido pelas escolas da rede estadual para melhorar o padrão de desempenho dos alunos do ensino médio, foi instituído o 
Prêmio Aprender pra Valer, através da Lei n. 14.483, de 8 de outubro de 2009, com base nos resultados do Spaece, de acordo com os seguintes critérios: meta de evolução de 7 a 10\% sobre a média de proficiência obtida no ano anterior, em Língua Portuguesa e Matemática; não apresentar média de proficiência da escola no padrão "Muito crítico"; e percentual mínimo de $80 \%$ de participação. Esse prêmio beneficia todos os gestores, professores e servidores, com um salário adicional proporcional às taxas de crescimento. $O$ governo instituiu também o prêmio para os alunos do ensino médio, através da Lei n.14.483, de 08 de outubro de 2009, com base nos resultados do Spaece, considerando os seguintes critérios: média de 325 pontos em Língua Portuguesa e de 350 pontos em Matemática (nível “Adequado”). O referido prêmio consiste na entrega de um microcomputador para todo aluno que atingir as referidas médias.

\section{INOVAÇÕES IMPLEMENTADAS}

Observa-se que a partir de 2007 ocorreu a maior e mais significativa mudança no Spaece-Alfa em relação à sua abrangência, uma vez que pela primeira vez a avaliação do sistema passa a ser censitária e universal. Ou seja, envolve todas as escolas públicas e todos os alunos dos 184 municípios cearenses. Até então, a avaliação do Spaece era somente censitária para as escolas, isto é, contemplava o universo de todas as escolas públicas das séries avaliadas, mas retirava uma amostra representativa dos alunos de cada escola, sendo assim, portanto, uma avaliação amostral. Essa inovação possibilitou ao sistema educacional, e particularmente às escolas, o retrato do desempenho escolar de cada aluno avaliado.

Ainda na linha da ampliação da abrangência, a criação da nova vertente do Spaece-Alfa representou também uma das mais importantes inovações desse período, por possibilitar o diagnóstico das deficiências de leitura logo nos primeiros anos do ensino fundamental, aumentando assim as possibilidades de intervenções também no início do processo de alfabetização.

Outro aspecto importante observado foi a inclusão de todas as séries do ensino médio. No Brasil, o Sistema Nacional de Avaliação da Educação Básica (Saeb) e alguns sistemas estaduais de avaliação incluem somente a $3^{\mathrm{a}}$ série do ensino médio. Com efeito, o envolvimento das três séries do ensino médio $\left(1^{\mathrm{a}}, 2^{\mathrm{a}}\right.$, 
$3^{\mathrm{a}}$ séries) e a periodicidade anual da aplicação dos instrumentais da avaliação permitem o acompanhamento longitudinal dos alunos, detectando o progresso de aprendizagem de cada aluno avaliado, bem como em que medida cada escola consegue agregar valor à aprendizagem dos seus alunos, ou seja, a participação efetiva da escola no desempenho do aluno.

Convém ainda mencionar que a política de incentivo e premiação do governo atrelada aos resultados do Spaece tem sido indutora de mudanças nas práticas docentes e de gestão voltadas para elevar o padrão de ensino ofertado. A tendência de melhoria da participação dos alunos na avaliação, assim como nos desempenhos, reflete o visível interesse dos agentes educacionais que se mobilizam para provocar mudanças positivas nas escolas e no sistema de ensino.

\section{CICLOS DE AFERIÇÃO DO SPAECE}

Conforme já mencionado anteriormente, o Spaece é um dos sistemas estaduais de avaliação em larga escala pioneiro no Brasil. Criado em 1992, realizou em 2010 seu $14^{\text {a }}$ ciclo de aferição. Ao longo dos anos, o Spaece experimentou modificações e aprimoramentos, aumentando significativamente sua abrangência. Passou da experiência piloto realizada no município de Fortaleza, com 14.600 alunos, para um total de 743.389 alunos avaliados no último ciclo realizado em 2010. Tal abrangência é bem superior ao total de alunos envolvidos, no estado do Ceará, pelo Sistema Nacional de Avaliação da Educação Básica (Saeb), cujo público avaliado em 2009 foi de 255.029 alunos. Convém ressaltar como ponto forte do Spaece a regularidade dos ciclos realizados, mantendo certa periodicidade, continuidade da série histórica, assegurando o seu caráter de permanência ao longo dos anos. 
TABELA 1 - Ciclos de aferição do Spaece - 2007 a 2010 na determinação dos indicadores

\begin{tabular}{|c|c|c|c|}
\hline ANO & ABRANGÊNCIA & SÉRIE & $\begin{array}{l}\text { ALUNOS } \\
\text { AVALIADOS }\end{array}$ \\
\hline 2007 & $\begin{array}{l}\text { Universalizado (184 municípios) - } \\
\text { Redes Estadual e Municipal }\end{array}$ & $2^{\circ} \mathrm{EF}^{* *}$ & 2145.383 \\
\hline 2008 & $\begin{array}{l}\text { Universalizado (184 municípios) - } \\
\text { Redes Estadual e Municipal }\end{array}$ & $\begin{array}{l}2 \circ, 5^{\circ} \text { e } 9 \circ \mathrm{EF} \text { e } \\
1^{\mathrm{a}}, 2^{\mathrm{a}} \text { e } 3^{\mathrm{a}} \mathrm{EM} \mathrm{M}^{* * *}\end{array}$ & 614.556 \\
\hline 2009 & $\begin{array}{l}\text { Universalizado (184 municípios) - } \\
\text { Redes Estadual e Municipal }\end{array}$ & $\begin{array}{l}2^{\circ} \text { e } 5^{\circ} \mathrm{EFe} \\
1^{a}, 2^{\underline{a}} \text { e } 3^{\underline{a}} E M\end{array}$ & 640.000 \\
\hline $2010^{*}$ & $\begin{array}{l}\text { Universalizado (184 municípios) - } \\
\text { Redes Estadual e Municipal }\end{array}$ & 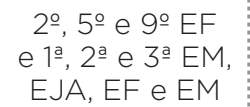 & 743.389 \\
\hline
\end{tabular}

(*) Caed/UFJF, dados preliminares, (**) Ensino Fundamental, $\left({ }^{* * *}\right)$ Ensino Médio.

Fonte: Elaborado pelo autor a partir de informações obtidas junto à Secretaria da Educação (CEARÁ, 2011).

\section{ABRANGÊNCIA E PARTICIPAÇÃO}

Na avaliação da Alfabetização, Spaece-Alfa, os dados indicam o melhor índice de participação dos alunos entre as vertentes avaliativas do Spaece, atingindo em 2010 o percentual de $98,6 \%$, quase a totalidade dos alunos previstos. Comparando-se a 2007, cuja participação foi de apenas 71,0\%, registra-se um aumento acumulado nos quatro anos de $27,6 \%$, o que demonstra o grande esforço de mobilização para assegurar a participação massiva dos alunos.

No $5^{\circ}$ ano do ensino fundamental o percentual de participação, em 2010, correspondeu a 97,4\%, segundo maior percentual de participação das avaliações do Spaece, o que representa um aumento de $9 \%$ se comparado a 2008. Já no $9^{\circ}$ ano a participação dos alunos em 2010 foi de $92,0 \%$, aumentando $12 \%$ quando comparado a 2008 , quando a participação foi somente de $79,9 \%$. Ressalte-se que, no ciclo de 2009, não houve avaliação dos alunos do $9^{\circ}$ ano devido ao seu caráter bienal.

Na avaliação do ensino médio, os dados revelam que 79,8\% dos alunos da $1^{\text {a }}$ série participaram do Spaece 2010. Esse percentual corresponde a um aumento de $12,3 \%$ em relação ao Spaece 2008. Na $2^{a}$ série, participaram $83,5 \%$, indicando um aumento acumulado de 11,3\% em relação a 2008. Contudo, a maior participação dos alunos do ensino médio foi na $3^{\mathrm{a}}$ série, atingindo $86,2 \%$ dos alunos em 2010, correspondendo a um aumento de 8,2\% em relação a 2009. 
TABELA 2 - Dados de participação das escolas e alunos no Spaece - 2010

\begin{tabular}{|c|c|c|c|c|c|}
\hline SÉRIE & REDE & $\begin{array}{c}\text { No DE } \\
\text { ESCOLAS }\end{array}$ & $\begin{array}{c}\text { ALUNOS } \\
\text { PREVISTOS }\end{array}$ & $\begin{array}{c}\text { ALUNOS } \\
\text { AVALIADOS }\end{array}$ & $\begin{array}{c}\text { (\%) DE } \\
\text { PARTICIPAÇÃO }\end{array}$ \\
\hline $2^{\circ} \mathrm{EF}$ & Pública & 5.543 & 126.215 & 124.495 & 98,6 \\
\hline $5^{\circ} \mathrm{EF}$ & Pública & 5.133 & 138.457 & 134.820 & 97,4 \\
\hline $9^{\circ} \mathrm{EF}$ & Pública & 2.778 & 123.579 & 113.750 & 92,0 \\
\hline 1 $E M$ & Estadual & 537 & 144.660 & 115.456 & 79,8 \\
\hline $2^{a}$ EM & Estadual & 511 & 114.781 & 95.797 & 83,5 \\
\hline 3 EM & Estadual & 486 & 95.697 & 82.475 & 86,2 \\
\hline EJA EF & Estadual & - & - & 3.718 & - \\
\hline EJA EM & Estadual & & - & 5.430 & - \\
\hline Total & & - & 743.389 & 675.941 & 90,9 \\
\hline
\end{tabular}

Fonte: Elaboração da autora.

\section{PRINCIPAIS RESULTADOS ALCANÇADOS}

AVALIAÇÃO DA ALFABETIZAÇÃO (SPAECE-ALFA)

Os resultados gerais do estado do Ceará em relação à avaliação da alfabetização mostram avanços expressivos. A média de proficiência obtida pelos alunos do $2^{\circ}$ ano do ensino fundamental no ciclo de 2010 foi de 162,7 pontos, o que corresponde ao nível Desejável na escala de proficiência do Spaece, na qual são estabelecidos os Padrões de Desempenho Estudantil na Educação Básica (CAED, 2009). Comparando-se aos resultados de 2009, verifica-se um crescimento significativo de 20,2 pontos, o maior índice de crescimento anual nesses quatro anos. Em relação a 2007 , registra-se um crescimento acumulado de 43,8 pontos, demonstrando progressos de aprendizagem expressivos, passando do nível "Intermediário" em 2007 para o nível "Desejável" em 2010, evoluindo dois níveis de padrão de desempenho na escala.

A distribuição do percentual dos alunos no $2^{\circ}$ ano (Spaece-Alfa) por padrão de desempenho indica $54,9 \%$, ou seja, mais da metade dos alunos no nível "Desejável" e 15,8\% no nível "Suficiente", atingindo 70,7\% de alunos considerados alfabetizados ao término do $2^{\circ}$ ano, em 2010 . Vale ressaltar que esse percentual em 2007 era de apenas 39,8\% dos alunos.

Além disso, constata-se uma redução expressiva de alunos no nível "Não Alfabetizado", de 32,8\% em 2007, para 6,9\% em 2009 , representando uma redução de $25,9 \%$ de alunos nesse nível, conforme pode ser observado na tabela a seguir: 
TABELA 3 - Média de proficiência em Leitura e distribuição por padrão de desempenho dos alunos do $2^{\circ}$ ano do ensino fundamental da rede municipal do Ceará, Spaece 2007/2009

\begin{tabular}{|c|c|c|c|c|c|c|c|}
\hline SÉRIE & ANO & MÉDIA & $\begin{array}{c}\text { NÃO } \\
\text { ALFAB. } \\
(A B A I X O 75)\end{array}$ & $\begin{array}{c}\text { ALFAB } \\
\text { INCOMPL. } \\
\text { (75 A 100) }\end{array}$ & $\begin{array}{l}\text { INTERMEDIÁRIO } \\
\quad(100 \text { A 125) }\end{array}$ & $\begin{array}{l}\text { SUFICIENTE } \\
(125 \text { A 150) }\end{array}$ & $\begin{array}{l}\text { DESEJÁVEL } \\
(150 \text { ACIMA) }\end{array}$ \\
\hline \multirow[t]{4}{*}{$2^{\circ} \mathrm{EF}$} & 2007 & 118,9 & 32,8 & 114,6 & 12,7 & 9,9 & 29,9 \\
\hline & 2008 & 127,7 & 20,0 & 16,2 & 17,3 & 15,7 & 30,8 \\
\hline & 2009 & 142,5 & 14,4 & 14,0 & 15,7 & 14,5 & 41,5 \\
\hline & $2010^{*}$ & 162,7 & 6,9 & 9,4 & 13,0 & 15,8 & 54,9 \\
\hline
\end{tabular}

$\left(^{*}\right)$ Caed/UFJF, dados preliminares.

Fonte: Elaborado pelo autor a partir de informações obtidas junto à Secretaria da Educação (CEARÁ, 2011)

\section{AVALIAÇÃO DO ENSINO FUNDAMENTAL - 5 E 9응 ANO}

Os resultados das médias de proficiência dos alunos do $5^{\circ}$ ano do ensino fundamental também mostram uma tendência de melhoria. Em 2010, a média obtida na rede pública no estado em Língua Portuguesa foi de 175,4 pontos e em Matemática de 189,3 pontos. Embora as médias se situem aquém do nível "Adequado", ou seja, nos níveis "Intermediário" e "Crítico", respectivamente, os dados sinalizam uma melhoria gradativa no desempenho dos alunos. Em relação aos resultados de 2009, registra-se um crescimento de 3,7 pontos em Língua Portuguesa e 11,7 pontos em Matemática. Se comparados a 2004, observa-se um crescimento acumulado de 24,0 pontos em Língua Portuguesa e 31,7 pontos em Matemática. Embora a disciplina de Matemática tenha experimentado um crescimento maior, seu déficit de aprendizagem permanece maior que em Língua Portuguesa.

Na distribuição do percentual dos alunos por padrão de desempenho, em Língua Portuguesa, observou-se que 10,9\% dos alunos estão no nível "Muito crítico" em 2009, apresentando uma leve redução em relação a 2009 que foi de 13,0\%. No nível "Crítico" esse percentual atingiu 42,3\%, permanecendo praticamente inalterado em relação a 2008, que foi de $42,0 \%$. Esse mesmo comportamento se observa no nível "Intermediário", que em 2009 era de 34,9\% e em 2010 decresceu para 34,1\% dos alunos. Já no nível "Adequado", observa-se uma leve melhoria, passando de 10,1\% em 2009 para 12,6\% em 2010. Se comparado a 2004, constata-se uma melhoria significativa nos percentuais de alunos nos níveis "Intermediário" e “Adequado", passando de 28,7\% em 2004, para 46,7\% em 2010. Em Matemática, observa-se a mesma tendência de redução 
nos níveis mais baixo da escala, que representava $72,9 \%$ dos alunos nos níveis "Muito crítico" e "Crítico" em 2009, diminuindo para $63,6 \%$ em 2010. Se comparado a 2004 , que tinha $85,3 \%$ dos alunos nessa situação, observa-se uma redução acumulada de 21,7\% nesse período. Nos níveis mais elevados da escala, ou seja, "Intermediário" e "Adequado", atingiu-se 36,4\% dos alunos em 2010, superando o obtido em 2009, que foi de $27,1 \%$, e, mais ainda, ao obtido em 2004, que era apenas de 14,7\% dos alunos. Apesar dessa evolução, a concentração dos alunos em situação de melhor aprendizagem em Matemática $(36,4 \%)$ é ainda mais baixo que em Língua Portuguesa $(46,7)$.

No $9^{\circ}$ ano do ensino fundamental, os resultados do ciclo do Spaece realizados em 2010, envolvendo essa série/ano, revelam que a média obtida em Língua Portuguesa foi de 223,0 pontos e em Matemática, 232,7 pontos, ambas situadas no nível "Crítico" da escala. Comparado a 2008, observa-se que em Língua Portuguesa houve uma evolução de 6,7 pontos, e em Matemática de 7,7 pontos. Em relação a 2004, registra-se um crescimento acumulado de 18,6 pontos em Língua Portuguesa e de 8,6 pontos em Matemática.

Quanto à distribuição do percentual de alunos por nível de desempenho, constatou-se que em 2010, em Língua Portuguesa, apenas 4,7\% dos alunos se encontram no nível "Adequado", contra 31,7\% que ainda permanecem no nível "Muito crítico". Entretanto, registra-se uma leve melhoria nesses indicadores, quando comparados com a realidade de 2008. Analisando o grupo dos alunos que se encontravam nos níveis "Muito crítico" e "Crítico" em 2010, que era de 71,8\%, é menor que o percentual registrado em 2004 , que era de $83,9 \%$. Essa melhoria também é observada no percentual de alunos nos níveis "Intermediário" e "Adequado", que aumentou de 16,1\% em 2004 para $28,1 \%$ em 2010. Em Matemática, no ciclo de 2010, também se registra movimento semelhante de melhoria dos indicadores extremos da escala, ou seja, houve um aumento de 1,6\% dos alunos em 2008 para 2,9\% em 2010 no nível "Adequado", bem como uma redução no nível "Muito Crítico", de 51,9\% para 46,6\% no mesmo período. Verifica-se que o quantitativo de alunos posicionados nos níveis "Muito crítico" e "Crítico", em 2010, é de $82,6 \%$, contudo menor que o percentual de alunos nesses níveis se comparado ao ano de 2004 , que era de $91,7 \%$. Nos níveis 
"Intermediário" e "Adequado" também se registra uma ligeira melhoria, uma vez que em 2004 somente 8,3\% se encontravam nesses níveis, passando para 17,4\% em 2010. Percebe-se que a distribuição do percentual de desempenho dos alunos, principalmente em Matemática, está mais concentrada no nível mais baixo da escala de proficiência do Spaece.

Todos esses indicadores, tanto do $5^{\circ}$ ano como do $9^{\circ}$ ano do ensino fundamental, são verificados nas tabelas das médias em Língua Portuguesa e Matemática a seguir:

TABELA 4 - Média de proficiência em Língua Portuguesa e distribuição por padrão de desempenho dos alunos do $5^{\circ}$ e $9^{\circ}$ ano do ensino fundamental da rede pública do Ceará, Spaece 2004/2009

\begin{tabular}{|c|c|c|c|c|c|c|}
\hline SÉRIE & ANO & MÉDIA & $\begin{array}{c}\text { MUITO } \\
\text { CRÍTICO } \\
\text { (ABAIXO 125) }\end{array}$ & $\begin{array}{l}\text { CRÍTICO } \\
\text { (125 A 175) }\end{array}$ & $\begin{array}{c}\text { INTERMEDIÁRIO } \\
(175 \text { A 225) }\end{array}$ & $\begin{array}{l}\text { ADEQUADO } \\
\text { (225 ACIMA) }\end{array}$ \\
\hline \multirow[t]{5}{*}{$5 \circ \mathrm{EF}$} & 2004 & 151,4 & 30,8 & 40,6 & 22,9 & 5,8 \\
\hline & 2006 & 151,5 & 26,9 & 47,7 & 21,6 & 3,9 \\
\hline & 2008 & 168,1 & 12,3 & 47,2 & 33,6 & 6,9 \\
\hline & 2009 & 171,7 & 13,0 & 42,0 & 34,9 & 10,1 \\
\hline & $2010 *$ & 175,4 & 10,9 & 42,3 & 34,1 & 12,6 \\
\hline \multirow[t]{4}{*}{$9 \circ \mathrm{EF}$} & 2004 & 204,4 & 46,6 & 46,6 & 14,1 & 2,0 \\
\hline & 2006 & 212,3 & 38,9 & 38,9 & 16,9 & 2,3 \\
\hline & 2008 & 216,3 & 35,1 & 35,1 & 18,0 & 2,5 \\
\hline & $2010^{*}$ & 223,0 & 31,7 & 31,7 & 23,4 & 4,7 \\
\hline
\end{tabular}

* Caed/UFJF, dados preliminares.

Fonte: Elaborado pelo autor a partir de informações obtidas junto à Secretaria da Educação (CEARÁ, 2011)

TABELA 5 - Média de proficiência em Matemática e distribuição por padrão de desempenho dos alunos do $5^{\circ}$ e $9^{\circ}$ ano do ensino fundamental da rede pública do Ceará, Spaece 2004/2009

\begin{tabular}{|c|c|c|c|c|c|c|}
\hline SÉRIE & ANO & MÉDIA & $\begin{array}{c}\text { MUITO } \\
\text { CRÍTICO } \\
\text { (ABAIXO 150) }\end{array}$ & $\begin{array}{l}\text { CRÍTICO } \\
(150 \text { A 200) }\end{array}$ & $\begin{array}{c}\text { INTERMEDIÁRIO } \\
(200 \mathrm{~A} \text { 250) }\end{array}$ & $\begin{array}{l}\text { ADEQUADO } \\
(250 \text { ACIMA) }\end{array}$ \\
\hline \multirow[t]{5}{*}{ 5 ㅌ EF } & 2004 & 157,6 & 46,1 & 39,2 & 12,5 & 2,2 \\
\hline & 2006 & 166,3 & 32,6 & 53,3 & 13,0 & 1,1 \\
\hline & 2008 & 169,9 & 33,4 & 46,7 & 16,3 & 3,6 \\
\hline & 2009 & 177,6 & 28,4 & 44,5 & 20,4 & 6,7 \\
\hline & $2010^{*}$ & 189,3 & 19,6 & 44,0 & 26,1 & 10,3 \\
\hline \multirow[t]{4}{*}{$9^{\circ} \mathrm{EF}$} & 2004 & 224,1 & 53,7 & 38,0 & 7,3 & 1,0 \\
\hline & 2006 & 224,1 & 55,9 & 35,0 & 8,1 & 1,0 \\
\hline & 2008 & 225,0 & 51,9 & 34,8 & 11,7 & 1,6 \\
\hline & $2010^{*}$ & 232,7 & 46,6 & 36,0 & 14,5 & 2,9 \\
\hline
\end{tabular}

* Caed/UFJF, dados preliminares.

Fonte: Elaborado pelo autor a partir de informações obtidas junto à Secretaria da Educação (CEARÁ, 2011) 


\section{AVALIAÇÃO DO ENSINO MÉDIO}

No ensino médio, os resultados gerais em Língua Portuguesa em 2010, na $1^{\text {a }}$ série, correspondem a uma média de 244,5 pontos, enquanto que em 2009 essa média foi de 240,6 pontos, portanto observa-se um crescimento de 3,9 pontos no desempenho geral dos alunos. Já em Matemática, na $1^{\text {a }}$ série do ensino médio corresponde a uma média de 244,0 pontos, ao passo que em 2009 essa média foi de 238,8 pontos, portanto observa-se um ligeiro crescimento de 5,2 pontos no desempenho geral dos alunos.

Em relação à $2^{\mathrm{a}}$ série, a média de proficiência em Língua Portuguesa em 2010 corresponde a 252,5 pontos, já em 2009 essa média foi de 248,5 pontos, aumentando em 4,0 pontos o desempenho geral dos alunos. Em Matemática, a média corresponde a 254,5 pontos, ao passo que em 2009 essa média foi de 253,2 pontos, aumentando em apenas 1,3 pontos o desempenho geral dos alunos, permanecendo praticamente inalterada.

Por sua vez, a média obtida em Língua Portuguesa na $3^{\mathrm{a}}$ série do ensino médio corresponde a 260,0 pontos em 2010, representando um aumento de 8,4 pontos em relação à média obtida em 2009, que foi de 251,6 pontos. Em Matemática, na $3^{\text {a }}$ série do ensino médio, a média obtida corresponde a 259,3 pontos, já em 2009 essa média foi de 260,4 pontos. Portanto, observa-se um leve decréscimo de 1,1 pontos no desempenho geral dos alunos, mantendo também quase o mesmo resultado.

Em termos de distribuição do desempenho dos alunos nos níveis da escala, os dados revelam, ainda em Língua Portuguesa na $3^{\mathrm{a}}$ série do ensino médio, uma concentração elevada de percentual de desempenho dos alunos nos níveis mais baixos da escala de proficiência, "Muito crítico" e "Crítico", correspondendo, respectivamente, a $23,2 \%$ e $37,8 \%$. Contudo, há sinais de melhoria na distribuição dos percentuais de desempenho quando comparamos com os resultados anteriores da série histórica, particularmente de 2008, na qual se observa uma maior concentração no nível "Muito crítico" da escala, e em 2009 a maior concentração encontra-se no nível "Crítico", o que significa que houve um avanço no nível da escala, vislumbrando-se uma tabela mais positiva para se atingir ao nível que se espera para essa série, no caso, o nível “Adequado”. Em relação a 2004, constata-se um crescimento acumulado de 23,1\% nos níveis "Intermediário" e "Adequado" durante o período. 
Em Matemática, observa-se uma elevada concentração nos níveis mais baixos da escala de proficiência, "Muito crítico" e "Crítico", respectivamente de $46,9 \%$ e $32,5 \%$. O somatório deste conjunto, $79,4 \%$, manteve-se exatamente igual ao registrado em 2009, tendo aumentado um pouco mais a concentração no menor nível da escala. Em contrapartida, verifica-se um ligeiro aumento no nível "Adequado", passando de 4,7\% para 5,2\%, em 2010. Em relação a 2004, constata-se um crescimento acumulado de 6,4\% nos níveis "Intermediário" e "Adequado", menor do que o observado em Língua Portuguesa no mesmo período. Essas informações podem ser constatadas nas tabelas de Língua Portuguesa e Matemática, apresentados a seguir:

TABELA 6 - Média de proficiência em Língua Portuguesa e distribuição por padrão de desempenho dos alunos da $1^{a}, 2^{a} 3^{a}$ séries do ensino médio da rede estadual do Ceará, Spaece 2004/2009

\begin{tabular}{|c|c|c|c|c|c|c|}
\hline SÉRIE & ANO & MÉDIA & $\begin{array}{c}\text { MUITO } \\
\text { CRÍTICO } \\
\text { (ABAIXO 225) }\end{array}$ & $\begin{array}{l}\text { CRÍTICO } \\
\text { (225 A 275) }\end{array}$ & $\begin{array}{l}\text { INTERMEDIÁRIO } \\
\quad(175 \text { A 225) }\end{array}$ & $\begin{array}{c}\text { ADEQUADO } \\
\text { (325 ACIMA) }\end{array}$ \\
\hline \multirow[t]{3}{*}{$1^{a} \mathrm{EM}$} & 2008 & 226,2 & - & - & - & - \\
\hline & 2009 & 240,6 & - & - & - & - \\
\hline & $2010^{*}$ & 244,5 & - & - & - & - \\
\hline \multirow[t]{3}{*}{ 2a $E M$} & 2008 & 229,0 & - & - & - & - \\
\hline & 2009 & 248,5 & - & - & - & - \\
\hline & $2010^{*}$ & 252,5 & - & - & - & - \\
\hline \multirow[t]{5}{*}{ 3르 } & 2004 & 229,5 & 47,2 & 36,8 & 14,1 & 1,8 \\
\hline & 2006 & 237,7 & 39,6 & 39,6 & 18,4 & 2,5 \\
\hline & 2008 & 235,4 & 42,8 & 36,8 & 17,6 & 2,8 \\
\hline & 2009 & 251,6 & 29,9 & 38,6 & 25,7 & 5,9 \\
\hline & $2010 *$ & 260,0 & 23,2 & 37,8 & 31,4 & 7,6 \\
\hline
\end{tabular}

* Caed/UFJF, dados preliminares.

Fonte: Elaborado pelo autor a partir de informações obtidas junto à Secretaria da Educação (CEARÁ, 2011) 
TABELA 7 - Média de proficiência em Língua Portuguesa e distribuição por padrão de desempenho dos alunos da $1^{\underline{a}}, 2^{\mathrm{a}} 3^{\mathrm{a}}$ séries do ensino médio da rede estadual do Ceará, Spaece 2004/2009

\begin{tabular}{|c|c|c|c|c|c|c|}
\hline SÉRIE & ANO & MÉDIA & $\begin{array}{c}\text { MUITO } \\
\text { CRÍTICO } \\
\text { (ABAIXO 225) }\end{array}$ & $\begin{array}{l}\text { CRÍTICO } \\
\text { (225 A 275) }\end{array}$ & $\begin{array}{c}\text { INTERMEDIÁRIO } \\
(175 \text { A 225) }\end{array}$ & $\begin{array}{l}\text { ADEQUADO } \\
\text { (325 ACIMA) }\end{array}$ \\
\hline \multirow[t]{3}{*}{$1^{\mathrm{a}} \mathrm{EM}$} & 2008 & 234,9 & - & - & - & - \\
\hline & 2009 & 238,8 & - & - & - & - \\
\hline & $2010 *$ & 244,0 & - & - & - & - \\
\hline \multirow[t]{3}{*}{$2^{\mathrm{a}} \mathrm{EM}$} & 2008 & 237,8 & - & - & - & - \\
\hline & 2009 & 253,2 & - & - & - & - \\
\hline & $2010^{*}$ & 254,5 & - & - & - & - \\
\hline \multirow[t]{5}{*}{ 3a EM } & 2004 & 254,3 & 49,8 & 36,0 & 12,0 & 2,1 \\
\hline & 2006 & 256,5 & 49,7 & 35,2 & 12,1 & 3,0 \\
\hline & 2008 & 247,9 & 55,7 & 30,0 & 11,7 & 2,5 \\
\hline & 2009 & 260,4 & 45,3 & 34,1 & 16,0 & 4,7 \\
\hline & $2010^{*}$ & 259,3 & 46,9 & 32,5 & 15,3 & 5,2 \\
\hline
\end{tabular}

* Caed/UFJF, dados preliminares.

Fonte: Elaborado pelo autor a partir de informações obtidas junto à Secretaria da Educação (CEARÁ, 2011).

\section{REFLEXÕES CONCLUSIVAS}

A leitura do contexto educacional local, a partir das informações levantadas, evidencia a longa caminhada do estado do Ceará no campo da avaliação educacional em larga escala, voltada para o diagnóstico da educação básica. Esse fato é um diferencial em relação à realidade educacional dos demais estados brasileiros, o que revela ser antiga e latente a preocupação em desvelar os problemas e desafios a serem enfrentados no setor educacional, bem como a sua vocação para com os processos de avaliação externa do seu sistema de ensino.

A visão dessa trajetória fornece os elementos para se compreender o contexto atual marcado pela presença de uma cultura de avaliação educacional, disseminada nas diferentes esferas que compõem o sistema educacional cearense. Nesse cenário, a avaliação educacional ganha força por ser uma prioridade política dos gestores maiores, fazendo-se refletir nas diversas outras políticas educacionais em curso.

Por sua vez, a avaliação passa a ser concebida como uma ferramenta estratégica de gestão do sistema para a melhoria dos indicadores educacionais, materializada pela utilização 
do modelo administrativo de gestão por resultados. Observa-se o uso da avaliação como instrumento indutor da melhoria da educação, explicitado, sobretudo, com a utilização dos resultados das avaliações atrelados a políticas de incentivo e premiação, com o propósito de motivar os agentes envolvidos no processo educacional.

Como consequência desse processo, o Estado passou a ter uma robusta bateria de dados, indicadores e informações educacionais impar no país. Tais resultados possibilitam ações de acompanhamento e monitoramento das diversas instâncias do sistema, bem como o desenvolvimento de políticas, programas e ações de intervenções focalizadas.

Os resultados produzidos nas avaliações desses quatro anos demonstram uma tendência acentuada e contínua de melhoria do desempenho em todas as séries e disciplinas avaliadas. Verifica-se que a melhoria no desempenho escolar é mais acentuada nas primeiras séries do ensino fundamental, particularmente no $2^{\circ}$ ano. Já no $5^{\circ}$ ano, embora tenha apresentado sinais de melhoria, constata-se ainda a existência de defasagens em relação aos níveis desejados para essa etapa de escolaridade. Por outro lado, esses resultados vislumbram, a médio e longo prazo, a possibilidade de melhoria dos desempenhos nos anos subsequentes, uma vez que se espera que os alunos tenham consolidado as habilidades básicas de leitura e escrita.

Contudo, em que pese as melhorias alcançadas recentemente, é oportuno refletir que a avaliação educacional por si só não é capaz de resolver os problemas da educação, mas fornece importantes elementos para nortear o processo de intervenção e transformação da realidade educacional existente, rompendo com obstáculos da baixa qualidade e equidade predominantes nos sistemas de ensino em nosso estado e em nosso país.

\section{REFERÊNCIAS}

CEARÁ, Secretaria da Educação. Bases de Dados das Avaliações do Spaece 2007/2010. Célula de Avaliação do Desempenho Acadêmico (Ceade/Seduc). Fortaleza, 2011.

EMIN, Jean-Claude. As Grandes linhas do dispositivo de avaliação do sistema educacional francês. In: ALMEIDA, Fernando José de (Org.). Avaliação educacional em debate: experiências no Brasil e na França. São Paulo: Cortez, 2005. p. 59-80. 
GENTILI, Pablo. Desencanto e utopia: a educação no labirinto dos novos tempos. Petrópolis, RJ: Vozes, 2008.

LIMA, Alessio Costa. O Sistema Permanente de Avaliação da Educação Básica do Ceará (Spaece) como expressão da política pública de avaliação educacional do estado. 248 f. Dissertação (Mestrado Acadêmico em Políticas Públicas e Sociedade) Universidade Federal do Ceará, Fortaleza, CE, 2007. Disponível em: <www. politicasuece.com/v6/admin/alunos/download.php?file=alessio.pdf $>$. Acesso em: 1 maio 2011.

LIMA, Alessio Costa; COELHO, Sylvia Maria de Aguiar; SOARES, Lindomar da Silva. Sistema Permanente de Avaliação da Educação Básica do Ceará: uma leitura dos resultados. In: Secretaria da Educação Básica do Ceará. Gestão para o sucesso escolar. Fortaleza: Seduc, 2005. 168p. (Coleção gestão escolar).

UNIVERSIDADE FEDERAL DE JUIZ DE FORA, Faculdade de Educação. Padrões de desempenho estudantil na educação básica: uma proposta preliminar e alguns comentários. Juiz de Fora, MG: Caed, 2009. Mimeo.

VIANNA, Heraldo Marelim. Introdução à avaliação educacional. São Paulo: Ibrasa, 1989.

ALESSIO COSTA LIMA

Doutorando em Educação, na área de Avaliação Educacional, na Universidade Federal do Ceará - UFC

alessio@seduc.ce.gov.br 